\title{
Environmental policy evaluation from the perspective of farmers' perception in arid oasis ecosystem: Experiences of Minqin, Northwest China
}

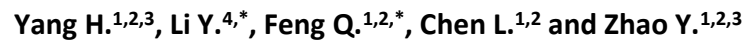 \\ ${ }^{1}$ Northwest Institute of Eco-Environment and Resources, Chinese Academy of Sciences, Lanzhou 730000, China \\ ${ }^{2}$ Key Laboratory of Ecohydrology of Inland River Basins, Chinese Academy of Sciences, Lanzhou 730000, China \\ 3 University of Chinese Academy of Sciences, Beijing 100049, China \\ ${ }^{4}$ School of Philosophy and Sociology, Lanzhou University, Lanzhou 730000, China \\ Received: 12/08/2016, Accepted: 14/09/2016, Available online: 03/10/2017 \\ *to whom all correspondence should be addressed: \\ e-mail: liyongjin@|zu.edu.cn (Y.J. Li); qifeng@Izb.ac.cn (Q. Feng)
}

\section{Abstract}

Effective eco-environment rehabilitation is an essential policy issue in arid oasis ecosystem. Since 2007, a policy which focuses on environment restoration and protection was implemented in the Shiyang River Basin of Gansu Province, China. Using Minqin oasis as a case, the effectiveness of policy impacts based on farmers' perception was evaluated. In addition, an ordinal logistic regression model was used to explore the potential factors affecting farmers' perception of policy effectiveness. Data were collected from household heads or spouses and other adults (age $>18$ ) separately in a random sample of 425 households. The results showed that positive outcomes were achieved, however, two policy measures-the water restrictions and the ecological migration project-were rated at a low level of satisfaction by the farmers. Moreover, 11 determinants were extracted by the logistic regression method, and indicating that economic factors including the ownership of the arable land and the availability of household income turned out to be the most significant. The results can help to establish ecoenvironmental restoration targets, encourage investments, and lead to the development of more applicable methods for assessing policy effects from the perspective of smallholders in ecologically fragile areas all over the world.
Keywords: Environmental policy evaluation; Farmers' perception; Ordinal logistic regression; Minqin oasis; Northwest China

\section{Introduction}

In arid inland river basin regions of the world, oasis is the dominant component because over $90 \%$ of human and other lives depend on it to survive, it is also an separate ecological system entity with water as its crux, and adequate water supply is the lifeline for the sustainability of the oasis to sustain the lives of local people, livestock and agriculture, as well as environmental health and ecosystem services (Xue et al., 2015). However, climate change, together with improper water-related human activities such as irrational land use, mismanagement of water resources, competition for water from industry and urbanization, rapid population growth (Khanmtr and Omprakash, 2016; Mouratidis et al., 2010; Ranatunga et al., 2014), and the variation in national oriented policies in different periods (Huang et al., 2014; Xue et al., 2015) are regarded as the fundamental factors affecting the hydrologic conditions that have caused a severe water scarcity in the oases of the inland river basins. Consequently, environment degradation caused by water resources crisis in arid oasis ecosystem currently becomes an overall and widespread problem. 
In order to restore the seriously damaged oasis ecosystem and curb its continuous damage tendency, a wide variety of national and regional policy measures have been implemented. Whereas, what are these policy measures implementation progress status, have the pre-identified objectives been met, and what effects have occurred? To answer these questions, a systematic and comprehensive evaluation is necessary, because policy-oriented environmental impact assessment has been recognized as an integral part of the early planning studies but also during project operation in order to identify any expected negative impacts and suggest the necessary mitigation actions to reduce these impacts (Manoliadis and Vatalis, 2003). Meanwhile, the periodic assessment of progress towards established policy goals is crucial to understand whether the applied efforts are effective. Moreover, timely policy evaluation can also help to assess whether current efforts are sufficient to reach the established objectives on time, and whether present practices are in fact aligned with the regulatory objectives agreed by both decision-makers and legislators (De Stefano et al., 2010).

At present, literature review on environmental policy evaluation reveals that a large volume of published studies strongly highlights the indicators orientation of results, focus on the choice of an adequate set of relevant indicators to describe the output, outcome, effects, efficient, cost-effectiveness, etc., while the actual practice has showed that indicator-oriented policy evaluation is only an "ideal type" (Maas et al., 2012). In contrast, understanding the degree to which local people find the policies acceptable and determine their attitude related to the project is a vital profile for policy evaluation; otherwise attempts to implement such projects may prove futile, or reduce the projects' effects (Feng et al., 2015). However, very few papers are concerned about quantitative-based research evaluations from the perspective of public perception. In view of this, our study attempts to assess the effects of environmental policy from farmers' standpoints. Because of local farmers as the grassroots stakeholders, who are not only the main implementation principal, but also are the direct beneficiaries of the eco-environmental restoration policy and program. Hence, local communities and indigenous people have an in-depth understanding of their environment, whose satisfaction evaluation can directly reflect the effects of the policy implementation. Therefore, satisfaction surveys from the perspective of farmers' perception can help policymakers to better understand the real needs and opinions of farmers, strengthen farmers' trust in government policy, and improve the applicability and flexibility of policy (Shui et al., 2014).

Environmental rehabilitation is an important issue in the fragile environment of the arid regions of northwest China (Feng et al., 2015). Minqin, a representative desert oasis, as a fragile ecological screen in inland region of northwest China, its ecological deterioration has drawn considerable attention from central government and all fields of society because the safety of it not only relates to local, but also to the whole northwest, and even nationwide ecological security. In this regard, in order to retrievably protect the Minqin oasis and to improve the ecological and environmental status of the Shiyang River Basin, an integrated governance policy named "the Key Governance Planning for the Shiyang River Basin" (KGPSRB), approved by the State Council of China, was launched in late 2007 and focuses on establishing a balance between water resources and demands on a basin scale basis. The KGPSRB is a systematic project, it covers a set of government measures that consist of closing some agricultural motorpumped wells and reducing the per capital arable land, returning farmland to forests or grasslands, prohibiting pasturing, preventing and controlling desertification, developing facilities for agriculture, and ecological migration, etc. The scheduled project goals were planned to be achieved in the implementation period, which was divided into two consecutive phases, i.e., 2006-2010 and 2010-2020. Planning a total investment of RMB 4.749 billion (695.6 million USD), the 1st phase investment was RMB 3.104 billion (454.7 million USD).

During implementation of this particular ecological rehabilitation project in an inland river basin, the success of the project will be problematic if project managers make no effective effort to understand local farmers' attitudes, views, and the degree of support for the project (Feng et al., 2015). An evaluation of farmers' satisfaction degree of the effect of policy measures can help to better understand the effectiveness of policy implementation and further enhance farmers' enthusiasm to participate in ecological rehabilitation and environment protection. Additionally, the results of this study can provide empirical evidence for policy makers to timely revise and improve policy measures and planning, which will ultimately strengthen the effect of the KGPSRB implementation. 


\section{Study area}

Minqin oasis $\left(101^{\circ} 49^{\prime} \sim 104^{\circ} 12^{\prime} \mathrm{E}, 38^{\circ} 03^{\prime} \sim 39^{\circ} 27^{\prime} \mathrm{N}\right)$ is located in the lower reaches of the Shiyang River basin at the easternmost region of the Hexi Corridor in Gansu Province of northwest China. The total surface area of the oasis is $15,870 \mathrm{~km}^{2}$ and is surrounded in the north, west and east by the Badain Jaran and the Tengger Deserts (Figure 1). It functions as an important natural ecological barrier that resists desert encroachment (Danfeng et al., 2008; Ren et al., 2014). About $90 \%$ of this area is occupied by dune fields and desertification land; only a limited area (less than $10 \%$ of the oasis) is fertile land fed by the Shiyang River, which is the only source of surface water that has been used for irrigation in combination with the Hongya Mountain Reservoir built in 1958 (Feng et al., 2010). It had a population of 274,330 in 2013.

Minqin's climate belongs to temperate-desert type characterized by low precipitation, high potential evaporation, intense sunshine, and strong wind. The mean annual precipitation is $116 \mathrm{~mm}$, concentrated in June through September, but the mean annual potential evaporation exceeds $2,453 \mathrm{~mm}$, which is 21 times the mean annual precipitation. The mean annual temperature is 7.7 ${ }^{\circ} \mathrm{C}$ and the mean annual wind speed is $2.4 \mathrm{~m} \mathrm{~s}^{-1}$, with a maximum of $23.0 \mathrm{~m} \mathrm{~s}^{-1}$ (Dong et al., 2010).

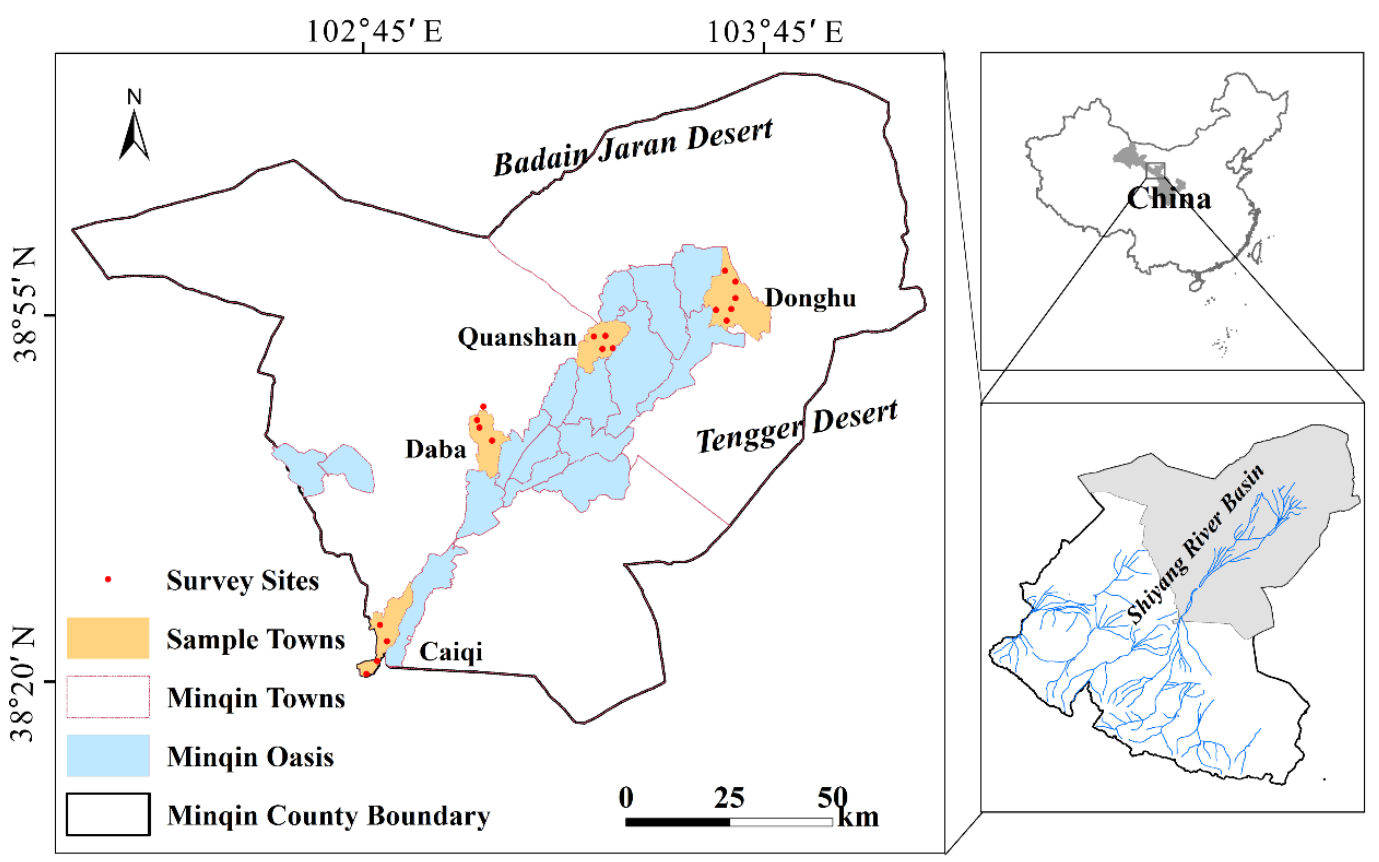

Figure 1. Location of the study area

\section{Materials and methods}

\subsection{Data collection}

The data were collected through a structured questionnaire survey in January 2013. A total of 450 formal questionnaires were distributed and 425 valid questionnaires were returned, resulting in a recovery ratio of $94.44 \%$. In the process of detailed sampling, a multistage stratified, random sampling method was utilized to select adults older than 18 as the respondents.

\subsection{Data analysis}

Data from the questionnaire were analyzed using the SPSS 19.0 statistical software. The analysis was carried out in three stages: descriptive statistics, correlation analysis, and ordinal logistic regression.

\subsection{Ordinal logistic model}

The ordinal logistic model is a straight forward extension of the logistic model for binary responses, which can be advantageous when the response variable is ordinal (Ananth and Kleinbaum, 1997). Because dichotomization can be somewhat arbitrary which may violate the underlying assumptions of the model; the arbitrariness is worsened in situations when the ordinal logistic model is fit to a response that has many ordered categories. Furthermore, the ordinal logistic model is the most flexible model for analyzing an ordinal response. 
There are several different regression models for ordinal response variables. In this study, we employed the proportional odds model (POM) to explore the potential influencing factors that affect the farmers' perception of the policy effectiveness. According to Anderson and Philips (1981) the model can be formulated as follows:

$$
\mathrm{Y}^{*}=\mathrm{X}^{\prime} \beta^{\top}+\varepsilon
$$

where $\mathrm{Y}^{*}$ is a theoretically unobservable continuous variable that depends on a vector of explanatory variables $\mathrm{X}^{\prime}=\left(\mathrm{x}_{1}, \mathrm{x}_{2}, \cdots, \mathrm{x}_{\mathrm{p}}\right)^{\top}$, and $\mathrm{p}$ is the number of independent variables in the model; $\beta^{\top}=\left(\beta_{1}, \beta_{2}, \cdots, \beta_{p}\right)^{\prime}$ is a $p$-vector of unknown regression parameters; and $\varepsilon$ is a stochastic error. The observed ordinal response variable is

$$
Y=j \quad \text { If } \alpha_{j-1}<Y^{*} \leq \alpha_{j}, \quad j \in(1,2, \cdots, J)
$$

where $\mathrm{Y}=(1,2, \cdots, \mathrm{J})$ has $\mathrm{J}$ possible categories; $\alpha_{j}(j=1,2, \cdots, J-1)$ are the unobserved thresholds or cutpoints with $\alpha_{1}<\alpha_{2}<\cdots<\alpha_{J-1}$. Because the POM is based on the concept of the cumulative logit model, combining (1) and (2) can yield a cumulative distribution function (CDF)

$$
\mathrm{P}\left(\mathrm{Y} \leq \mathrm{j} \mid \mathrm{X}^{\prime}\right)=\mathrm{P}\left(\mathrm{Y}^{*} \leq \alpha_{\mathrm{j}}\right)=\mathrm{P}\left(\mathrm{X}^{\prime} \beta^{\top}+\varepsilon \leq \alpha_{\mathrm{j}}\right)=\mathrm{P}\left(\varepsilon \leq \alpha_{\mathrm{j}}-\mathrm{X}^{\prime} \beta^{\top}\right)=\phi \beta \alpha_{\mathrm{j}}-\mathrm{X}^{\mathrm{s}}
$$

Then we can calculate the accumulated probability of the dependent variable $(\mathrm{Y})$ that will fall into the jth category or lower.

$$
P\left(Y \leq j \mid X^{\prime}\right)=\frac{\exp \left(\alpha_{j}-X^{\prime} \beta^{\top}\right)}{1+\exp \left(\alpha_{j}-X^{\prime} \beta^{\top}\right)}, j=1,2, \cdots, J
$$

This is equivalent to the multivariate logit form, which is a linear function of the $p$ independent variables

$$
\ln \left(\frac{P\left(Y \leq j \mid X^{\prime}\right)}{1-P\left(Y \leq j \mid X^{\prime}\right)}\right)=\mu_{j}-X^{\prime} \beta^{\top}, j=1,2, \cdots, J
$$

where $P\left(Y \leq j \mid X^{\prime}\right)$ is the cumulative probability of the event $(\mathrm{Y} \leq \mathrm{j}), \quad \mu_{\mathrm{j}}$ is an unknown intercept parameter that satisfies the condition $\mu_{1} \leq \mu_{2} \leq \cdots \leq \mu_{\jmath}$, it is a combination of intercept parameters for a response variable in the jth category and the thresholds $\alpha_{j}$.

Above all, the fundamental assumption in the ordinal logistic model with proportional odds is that the relationship between each pair of groups of the dependent variable is the same; therefore, the positive characteristic of the POM is that its intercepts are different for each jth category, but the coefficients are the same, i.e. it summarize the association between the independent variables and the dependent variable using only one set of $\beta^{\top}$ (Fuks and Salazar, 2008).

\subsection{Explanatory variables}

The dependent variable in this study is the farmers' satisfaction levels with the effectiveness of the KGPSRB, measured mainly using a 5-point Likert-type scale with answers ranging from 1 to 5 that represent "extremely dissatisfied" and "highly satisfied", respectively. Furthermore, farmers' perception of the policy effectiveness is influenced by a number of factors. Table 1 shows the groups of variables and their associated hypotheses with regard to their influence on the levels of farmers' satisfaction of the KGPSRB based on the literature review and considering the local situation. Learning from many previous studies on famers' perception, attitude or intention (Karali et al., 2014; Kerselaers et al., 2013; Li et X' $\$$ (!),2014; Maraqa and Ghoudi, 2015), the predictors can be divided into several types. Accordingly, the independent variables in this study were divided into four types: demographic factors, economic characteristics, cognition of and attitude toward the policy, and social circumstances.

\section{Results}

\subsection{Farmers' perception of the effects of policy measures}

In order to determine farmers' perception of the effectiveness of these policy measures, we established a set of questions using a 5-point Likert-type scale comprised of a total of 6 items (Table 2) to measure each policy measure, and their answers ranged from 1 to 5 representing 'strongly disagree' to 'strongly agree', respectively. 
Table 1. Definition and descriptive statistics of variables used in the regression analysis

\begin{tabular}{|c|c|c|c|c|c|}
\hline $\begin{array}{l}\text { Variable name } \\
\text { (abbreviation) }\end{array}$ & Definition and codes & $\mathbf{N}$ & Mean & S.D. & $\mathrm{H}_{0}{ }^{\mathrm{a}}$ \\
\hline
\end{tabular}

DV: PERCEP farmers' satisfaction levels with the effects of the KGPSRB $425 \quad 3.61 \quad 0.97$

(1=extremely dissatisfied; $2=$ dissatisfied; 3=no opinion 4=satisfied,

$5=$ highly satisfied)

\begin{tabular}{|c|c|c|c|c|c|}
\hline \multicolumn{6}{|c|}{ Demographic factors } \\
\hline SEX & Sex of respondent ( $1=$ male; $2=$ female $\left.^{b}\right)$ & 425 & 1.05 & 0.23 & ? \\
\hline AGE & Age of respondent (years) & 425 & 49.18 & 9.16 & + \\
\hline EDU & $\begin{array}{l}\text { Level of school education ( } 1 \text { =uneducated; } 2=\text { primary; } 3=\text { junior; } \\
4=\text { senior; } 5=\text { junior college and above }{ }^{b} \text { ) }\end{array}$ & 425 & 3.55 & 1.06 & - \\
\hline HUKOU & Registered permanent resident $\left(1=\right.$ rural; $2=$ urban $\left.^{b}\right)$ & 425 & 1.08 & 0.27 & + \\
\hline LEADER & Whether served as a village leader ( $\left.1=y e s ; 2=n o^{b}\right)$ & 425 & 3.55 & 0.89 & + \\
\hline \multicolumn{6}{|c|}{ Economic characteristics } \\
\hline ARALAND & Amount of cultivated land (Mu, $1 \mathrm{Mu}=1 / 15 \mathrm{ha}$ & 417 & 12.13 & 4.86 & - \\
\hline IRRILAND & Amount of irrigated cropland (Mu) & 417 & 12.13 & 4.86 & - \\
\hline INCOME & 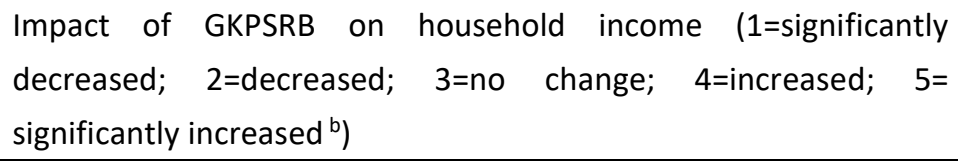 & 425 & 3.63 & 1.34 & - \\
\hline DEPOSIT & 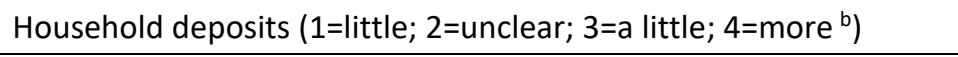 & 425 & 2.58 & 1.37 & - \\
\hline LOAN & Loans from the bank (1=yes; $2=$ no $^{\text {b }}$ ) & 425 & 1.26 & 0.45 & + \\
\hline \multicolumn{6}{|c|}{ Cognition of and attitude towards policies } \\
\hline RESTRWAT & Water restrictions for agricultural production ( $1=y e s ; 2=$ no $^{\text {b }}$ ) & 425 & 1.00 & 0.00 & - \\
\hline WATQUA & $\begin{array}{l}\text { Water quality for agricultural production ( } 1=\text { very poor; } 2=\text { only } \\
\text { irrigation; } 3=\text { drinkable; } 4=\text { higher standards }^{\text {b }} \text { ) }\end{array}$ & 425 & 2.79 & 0.78 & - \\
\hline FACIAGRI & Developing controlled environment agriculture ( $1=y e s ; 2=$ no $^{\text {b }}$ ) & 425 & 1.84 & 0.37 & + \\
\hline SURLABO & Surplus labor of household (1=yes; $2=$ no $^{\text {b }}$ ) & 425 & 1.55 & 0.50 & - \\
\hline TIMEAG & Time engaged in agricultural production in 2012 (months) & 417 & 7.82 & 1.78 & + \\
\hline SUBSIDY & Governmental subsidies $\left(1=y e s ; 2=\right.$ no $\left.^{b}\right)$ & 425 & 1.05 & 0.23 & + \\
\hline INTENMIG & Intention of emigration from the village $\left(1=y e s, 2=n^{b}\right)$ & 424 & 1.82 & 0.39 & - \\
\hline PRIDICENVI & $\begin{array}{l}\text { Prediction of environmental change in the future }(1=\text { sharp } \\
\text { deterioration; } 2=\text { some deterioration; } 3=\text { no change; } 4=\text { some } \\
\left.\text { amelioration; } 5=\text { considerable amelioration }{ }^{b}\right)\end{array}$ & 414 & 3.32 & 1.25 & - \\
\hline
\end{tabular}

Social circumstances

Access to policy information

\begin{tabular}{|c|c|c|c|c|c|}
\hline TV & Television ( $1=y e s, 2=$ no $^{b}$ ) & 424 & 1.34 & 0.48 & + \\
\hline INTNET & Internet (1=yes, $2=$ no $^{\mathrm{b}}$ ) & 424 & 1.95 & 0.23 & - \\
\hline BROAD & Radio broadcast ( $1=y e s, 2=$ no $^{b}$ ) & 424 & 1.95 & 0.23 & + \\
\hline NEWSP & Newspaper and magazine (1=yes, $2=$ no $\left.^{b}\right)$ & 424 & 1.71 & 0.46 & + \\
\hline PROPA & Disseminated by village administrator ( $1=y e s, 2=$ no $^{b}$ ) & 424 & 1.24 & 0.43 & ? \\
\hline NEIGHB & 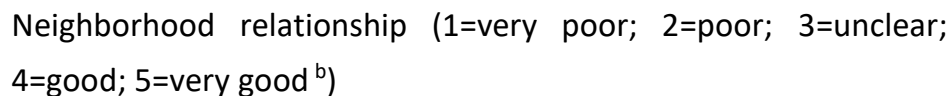 & 425 & 4.61 & 0.64 & - \\
\hline
\end{tabular}

a Denotes the expected sign of the coefficient for the relationship between DV and IVs, "+" denotes positive, "-" denotes negative, and "?" means indeterminate, b Denotes the reference category. 
Table 2. Items for measuring farmers' perception of policy effectiveness

\begin{tabular}{|c|c|c|}
\hline Policy measures & Measure items & $\begin{array}{l}\text { Evaluation } \\
\text { introduction }\end{array}$ \\
\hline $\begin{array}{l}\text { Water resource } \\
\text { allocation }\end{array}$ & Nowadays, the allocation of water resources is fair. & $\begin{array}{l}\text { 1= "strongly } \\
\text { disagree"; }\end{array}$ \\
\hline $\begin{array}{l}\text { - Structural changes in } \\
\text { crop planting }\end{array}$ & $\begin{array}{l}\text { Developing greenhouse agriculture and indoor husbandry can } \\
\text { improve household income. }\end{array}$ & $\begin{array}{l}\text { 2= "somewhat } \\
\text { disagree", }\end{array}$ \\
\hline $\begin{array}{l}\text { Closing motor-wells } \\
\text { and reducing irrigated } \\
\text { farming acreage }\end{array}$ & $\begin{array}{l}\text { The policy of closing the motor-wells and reducing the irrigated } \\
\text { farming acreage resulted in a large number of cultivated lands has } \\
\text { been abandoned and thereby decreased the household income } \\
\text { from agriculture. }\end{array}$ & $\begin{array}{l}3=\text { "no } \\
\text { opinion", } \\
4=\text { "somewhat } \\
\text { agree", }\end{array}$ \\
\hline $\begin{array}{l}\text { Pasture prohibition } \\
\text { and returning } \\
\text { farmland to forest or } \\
\text { grassland }\end{array}$ & $\begin{array}{l}\text { The policy of pasture prohibition and returning farmland to forest } \\
\text { or grassland can improve the local ecological environment. }\end{array}$ & $\begin{array}{l}5=\text { "strongly } \\
\text { agree" }\end{array}$ \\
\hline $\begin{array}{l}\text { - Preventing and } \\
\text { controlling the } \\
\text { spreading desert by } \\
\text { engineering measures }\end{array}$ & $\begin{array}{l}\text { Desertification control by engineering measures has considerably } \\
\text { improved the local eco-environment. }\end{array}$ & \\
\hline - $\quad$ Migration project & Ecological migration can relieve pressure on the environment. & \\
\hline
\end{tabular}

\subsection{Results of the logistic regression analysis}

The final estimated results of the multiple POM that was used to identify the variables affecting the probability of farmers' perception of policy effectiveness are presented in Tables 3 and 4 . There were a total of 24 variables in the regression model. Multicolinearity between the independent variables (IVs) was checked by correlation analysis; the absolute values of the Pearson's correlation coefficients were between 0.096 and 0.384 , indicating that none of the results exhibited signs of strong collinearity among the IVs.

The overall information of the model is presented in the bottom part of table 3 . We can see that the model fitting test value of $\chi^{2}$ was 384.277 and was highly significant ( $p<$ 0.0001 ) suggesting that at least one IV partial regression coefficient was not zero. For the Goodness-of-Fit, the test values of the Pearson and Deviance $\chi^{2}$ were 1558.945 and 81.769 , respectively, for which the $p$-values were not significant, indicating a good model fit. As for the Pseudo Rsquares, the Cox and Snell $R^{2}=0.620$, which demonstrated that together these independent variables explained $62.0 \%$ of the variance in the policy perception index among farmers in the study area. Furthermore, by testing parallel lines, the chi-square result of 124.552 ( $p=0.910$ ) was not significant, showing that the main assumption of the ordinal logistic regression was not violated, and the application of the POM in this study was appropriate.

The regression results provided 11 statistical significant determinants (marked using boldface in Table 3) that affected farmers' perception of policy effectiveness. The associations between the dependent variable and the 11 determinants were strongly significant $(p<0.05)$ except for the answer of 'some amelioration' for PRIDICENVI and the INTNET (yes vs. no), which had a relatively low significance level ( $p$-values were 0.058 and 0.065 , respectively, i.e., less than 0.10 ) but is theoretically important. The odds ratios (OR) that represent the estimated changes in the odds of the farmers' degree of satisfaction with policy effectiveness that are caused by a one unit increase in the respective explanatory variable while holding all other variables fixed are shown in Table 4.

\section{Discussion}

\subsection{Effects of the KGPSRB in Minqin oasis}

In contrast to previous studies, this is one of the first studies conducted in this study area to evaluate the environmental policy effectiveness from farmers' perception by using survey data. In this study, our research 
findings indicated that there were a few key differences for certain policy measures that were consistent with a previous study reported by Xue et al. (2015) that farmers did not welcome many of these new policies, such as drip irrigation, resettlement and closing of wells, and have even been met with passive resistance.

In our study, two of these policy measures were rated at a low level of satisfaction by the farmers, one is the water restriction and another is the ecological migration project. As to the former, because water is the life line of the oasis and no water no oasis, the water restriction caused many spillover effects and which is a chain reaction, such as the increase of ecological water use has reduced the water for agricultural production that made part of the farmland abandonment, reduction of cultivated land resulted in the farmers shift to non-agricultural livelihoods which not only increased pressure of farmland utilization but also adversely affected farmers' household livelihoods that their income decrease is the most direct result. Extensive survey data documented the reduced irrigated land made the farmers earned only $71 \%$ of their previous household income (Feng et al., 2015). For the latter, similar to the evidence from Burkina Faso on migration and technical efficiency in cereal production, the migrant households, migration has removed surplus young male labor leads to a gender imbalance in the household (Wouterse, 2010) that a cause for inefficiency in agricultural production. Therefore, the negative impacts of the policies connected to the projects caused dissatisfied attitudes.

\subsection{Association between farmers' perception of policy effectiveness and demographic factors as well as economic characteristics}

From the results of the ordinal logistic regression model, only one demographic factor, the LEADER, had a positive and significant correlation with farmers' perception of policy effectiveness. This can be explained by a special study based on the perspective of village leaders to evaluate the effects of policies implemented across vast rural areas (Luo, 2011) in China, which asserted that the village administrator, as the basic administrative unit in rural China, can obtain more comprehensive policy information derived from a top-down and bottom-up approach. Therefore, farmers who served as village leaders would have a better understanding of policy and a higher evaluation of policy effectiveness.
Five pre-identified independent variables belonging to economic characteristics were significant in the model. If we subdivide these predictors into two types on the basis of the Sustainable Livelihoods Framework Theory (Chambers and Conway, 1992), one group would represent the natural capital containing the gross arable land and irrigated cropland, and the other would represent the financial capital, consisting of annual income, deposits, and loans.

For the natural capital, arable land remains the main restrictive factor among natural resources required for agriculture, especially in arid areas (Li et al., 2014). In this study, however, an interesting finding revealed that the amount of arable land and irrigated land had an opposite impact on farmers' perception of policy effectiveness. The reason may be that the implementation of the ecoenvironmental rehabilitation policy has resulted in a reduction in rural household landholdings. According to the KGPSRB, the minimum irrigated land ownership for every farmer in Minqin oasis is $2.5 \mathrm{Mu}$ (0.17 ha) regardless of the total amount of arable land they had ever owned. As a consequence, the vast majority of farmers believed that the reallocation of irrigated land was fair; whilst some farmers, whose ownership of farmland considerably decreased, thought it reduced their income and stated their dissatisfaction of the policy effectiveness.

Regarding the financial capital, the study revealed that farmers with higher income and deposits tended to perceive the policy more effective, which is consistent with the survey results reported by Feng et al. (2015) that the poorer interviewees prefer to believe the policy greatly adversely affected their livelihoods. With respect to the loans, farmers who borrowed money from the bank were able to use it to improve their agricultural facilities and other infrastructure, which resulted in a successful transformation of traditional livelihoods and ultimately increased the standard of living.

5.3. Association between farmers' perception of policy effectiveness and predictors for cognition of and attitude toward the policy as well as social circumstances

Farmers' cognition of the policy and their attitude toward the effectiveness of policy measures are crucial for their satisfaction level of policy effects (Liu and Cai, 2014). Our findings demonstrated that three cognitive factor, i.e., water restrictions for agricultural production, developing greenhouse agriculture and prediction of environmental 
change in the future, negatively influenced farmers' satisfaction.

Table 3. Results of ordinal logistic regression for farmers' degree of perception of policy effectiveness

\begin{tabular}{|c|c|c|c|c|c|c|c|}
\hline \multirow{2}{*}{\multicolumn{2}{|c|}{ Variables (abbreviation) }} & \multirow{2}{*}{ B } & \multirow{2}{*}{ Std. error } & \multirow{2}{*}{ Wald } & \multirow{2}{*}{ Sig. } & \multicolumn{2}{|c|}{ 95\% Confidence Interval } \\
\hline & & & & & & Lower bound & Upper bound \\
\hline \multirow{4}{*}{$\begin{array}{c}\text { PERCEP } \\
\text { (thresholds) }\end{array}$} & $\mu_{1}{ }^{* *}$ & -6.557 & 2.065 & 10.083 & 0.001 & -10.605 & -2.510 \\
\hline & $\mu_{2}{ }^{*}$ & -4.525 & 2.050 & 4.871 & 0.027 & -8.544 & -0.507 \\
\hline & $\mu_{3}$ & -3.681 & 2.049 & 3.228 & 0.072 & -7.696 & 0.335 \\
\hline & $\mu_{4}$ & -1.394 & 2.037 & 0.468 & 0.494 & -5.387 & 2.599 \\
\hline \multirow[t]{2}{*}{ SEX } & Male & -0.004 & 0.169 & 0.001 & 0.980 & -0.337 & 0.328 \\
\hline & & 0.013 & 0.008 & 2.626 & 0.105 & -0.003 & 0.028 \\
\hline \multirow{4}{*}{ EDU } & Uneducated & 0.894 & 1.280 & 0.487 & 0.485 & -1.616 & 3.403 \\
\hline & Primary & 0.824 & 1.263 & 0.426 & 0.514 & -1.652 & 3.300 \\
\hline & Junior & 1.252 & 1.251 & 1.002 & 0.317 & -1.200 & 3.704 \\
\hline & Senior & 1.331 & 1.259 & 1.119 & 0.290 & -1.135 & 3.798 \\
\hline HUKOU & Yes & -0.378 & 0.271 & 1.949 & 0.163 & -0.910 & 0.153 \\
\hline \multirow{2}{*}{$\begin{array}{l}\text { LEADER } \\
\mathrm{AP}\end{array}$} & Yes $^{* *}$ & 3.236 & 1.223 & 7.005 & 0.008 & 0.840 & 5.632 \\
\hline & $\mathrm{ND}^{* * *}$ & -0.184 & 0.048 & 14.700 & 0.000 & -0.278 & -0.090 \\
\hline \multicolumn{2}{|c|}{ IRRILAND ${ }^{* * *}$} & 0.186 & 0.047 & 15.718 & 0.000 & 0.094 & 0.277 \\
\hline \multirow{4}{*}{ INCOME } & $\begin{array}{l}\text { Significantly } \\
\text { decreased }^{*}\end{array}$ & -0.938 & 0.384 & 5.952 & 0.015 & -1.691 & -0.184 \\
\hline & Decreased $^{* *}$ & -1.137 & 0.388 & 8.596 & 0.003 & -1.897 & -0.377 \\
\hline & No change & -0.266 & 0.466 & 0.326 & 0.568 & -1.179 & 0.647 \\
\hline & Increased $^{* *}$ & -1.062 & 0.381 & 7.755 & 0.005 & -1.810 & -0.315 \\
\hline \multirow{3}{*}{ DEPOSIT } & Little L $^{* * *}$ & -0.196 & 0.268 & 16.737 & 0.000 & -1.621 & -0.571 \\
\hline & Unclear $^{* *}$ & -0.648 & 0.236 & 7.523 & 0.006 & -1.111 & -0.185 \\
\hline & A little ${ }^{* * *}$ & -1.352 & 0.333 & 16.441 & 0.000 & -2.005 & -0.698 \\
\hline LOAN & Yes $^{* * *}$ & 0.562 & 0.150 & 14.083 & 0.000 & 0.269 & 0.856 \\
\hline RESTRWAT & Yes* & -1.020 & 0.505 & 4.072 & 0.044 & -2.010 & -0.029 \\
\hline \multirow{3}{*}{ WATQUA } & Very poor & -0.112 & 1.296 & 0.007 & 0.931 & -2.652 & 2.429 \\
\hline & Only irrigation & 0.415 & 0.985 & 0.178 & 0.673 & -1.515 & 2.346 \\
\hline & Drinkable & 0.169 & 0.181 & 0.877 & 0.349 & -0.185 & 0.524 \\
\hline FACIAGRI & Yes $^{*}$ & -0.481 & 0.199 & 5.850 & 0.016 & -0.871 & -0.091 \\
\hline SURLABO & Yes & -0.049 & 0.142 & 0.120 & 0.729 & -0.328 & 0.229 \\
\hline \multicolumn{2}{|c|}{ TIMEAG } & 0.021 & 0.031 & 0.455 & 0.500 & -0.040 & 0.081 \\
\hline SUBSIDY & Yes & -0.714 & 0.501 & 2.029 & 0.154 & -1.695 & 0.268 \\
\hline INTENMIG & Yes & 0.194 & 0.184 & 1.107 & 0.293 & -0.167 & 0.555 \\
\hline \multirow{4}{*}{ PRIDICENVI } & $\begin{array}{c}\text { Sharply } \\
\text { deterioration }^{* * *}\end{array}$ & -2.348 & 0.420 & 31.336 & 0.000 & -3.170 & -1.526 \\
\hline & $\begin{array}{c}\text { Some } \\
\text { deterioration }^{* *}\end{array}$ & -1.151 & 0.363 & 10.067 & 0.002 & -1.862 & -0.440 \\
\hline & No change $^{* *}$ & -1.057 & 0.376 & 7.905 & 0.005 & -1.793 & -0.320 \\
\hline & Some amelioration & -0.626 & 0.330 & 3.606 & 0.058 & -1.272 & 0.020 \\
\hline TV & Yes & -0.040 & 0.159 & 0.063 & 0.802 & -0.352 & 0.272 \\
\hline INTNET & Yes & -1.094 & 0.592 & 3.408 & 0.065 & -2.255 & 0.068 \\
\hline BROAD & Yes & 0.156 & 0.443 & 0.124 & 0.725 & -0.712 & 1.024 \\
\hline NEWSP & Yes & -0.414 & 1.305 & 0.101 & 0.751 & -2.973 & 2.144 \\
\hline PROPA & Yes* & 0.319 & 0.160 & 3.959 & 0.047 & 0.005 & 0.638 \\
\hline \multirow{4}{*}{ NEIGHB } & Very poor & 0.178 & 0.902 & 0.039 & 0.844 & -1.590 & 1.946 \\
\hline & Poor & -0.589 & 0.384 & 2.349 & 0.125 & -1.342 & 0.164 \\
\hline & Unclear & -0.090 & 0.712 & 0.016 & 0.900 & -1.485 & 1.305 \\
\hline & Good & -0.079 & 0.151 & 0.271 & 0.602 & -0.374 & 0.217 \\
\hline
\end{tabular}

Model fitting information: $\chi^{2}=384.227, d f=9, p=0.000^{* * *}$; link function: complementary.

Goodness-of-Fit: Pearson $\chi^{2}=1558.945, p=0.329^{\text {NS }}$; Deviance $\chi^{2}=819.769, p=1.000^{\text {NS }}$.

Pseudo R-square: Cox and Snell $R^{2}=0.620$; Nagelkerke $R^{2}=0.676$; McFadden $R^{2}=0.389$.

Test of parallel lines: $\chi^{2}=124.552, p=0.910, p=0.910^{\text {NS }}$.

" $p<0.05,{ }^{* *} p<0.01,{ }^{* * *} p<0.001$, Ns= "not significant"

This occurred firstly because water restrictions are a rigid requirement for the GKPSRB, which means that water use restrictions are imposed on all users in the area. Consequently, the livelihood sources of farmers' households that relied mainly on irrigated farming were the most directly affected. This is similar to the result found by Li et al. (2014) who conducted their study in the same area, indicating that the considerable reduction in arable land and water resources for agricultural production has resulted in a direct reduction in the natural capitals of the traditional livelihood of rural households. 
Table 4. Summary of estimated odds ratios of the significant independent variables

\begin{tabular}{|c|c|c|c|c|c|}
\hline Type & & ables (abbreviation) & OR/exp(B) & p-value & OR $95 \% \mathrm{Cl}$ \\
\hline \multirow{2}{*}{$\begin{array}{c}\text { Demographic } \\
\text { factors }\end{array}$} & \multirow{2}{*}{ LEADER $^{* *}$} & Yes & 25.43 & 0.008 & $2.32 \sim 279.22$ \\
\hline & & No & 1.00 & & \\
\hline \multirow{12}{*}{$\begin{array}{c}\text { Economic } \\
\text { characteristics }\end{array}$} & ARALAND*** & & 0.83 & 0.000 & $0.76 \sim 0.91$ \\
\hline & IRRILAND ${ }^{* * *}$ & & 1.20 & 0.000 & $1.10^{\sim} 1.32$ \\
\hline & \multirow{4}{*}{ INCOME } & Significantly decreased* & 0.39 & 0.015 & $0.18 \sim 0.83$ \\
\hline & & Decreased $^{* *}$ & 0.32 & 0.003 & $0.15^{\sim 0} 0.69$ \\
\hline & & Increased $^{* *}$ & 0.35 & 0.005 & $0.16^{\sim} 0.73$ \\
\hline & & Significantly increased (reference) & 1.00 & & \\
\hline & \multirow{4}{*}{ DEPOSIT } & Little ${ }^{* * *}$ & 0.82 & 0.000 & $0.20 \sim 0.56$ \\
\hline & & Unclear $^{* *}$ & 0.52 & 0.006 & $0.33 \sim 0.83$ \\
\hline & & A little ${ }^{* * *}$ & 0.26 & 0.000 & $0.13 \sim 0.50$ \\
\hline & & More (reference) & 1.00 & & \\
\hline & \multirow{2}{*}{$\operatorname{LOAN}^{* * *}$} & Yes & 1.75 & 0.000 & $1.31 \sim 2.35$ \\
\hline & & No (reference) & 1.00 & & \\
\hline \multirow{9}{*}{$\begin{array}{l}\text { Cognition and } \\
\text { attitude of policy }\end{array}$} & \multirow{2}{*}{ RESTRWAT* } & Yes & 0.36 & 0.044 & $0.13 \sim 0.97$ \\
\hline & & No (reference) & 1.00 & & \\
\hline & \multirow{2}{*}{ FACIAGRI $^{*}$} & Yes & 0.62 & 0.016 & $0.42 \sim 0.91$ \\
\hline & & No (reference) & 1.00 & & \\
\hline & \multirow{5}{*}{ PRIDICENVI } & Sharply deteriorated ${ }^{* * *}$ & 0.10 & 0.000 & $0.04 \sim 0.22$ \\
\hline & & Some deteriorated ${ }^{* *}$ & 0.32 & 0.002 & $0.16 \sim 0.64$ \\
\hline & & No change ${ }^{* *}$ & 0.35 & 0.005 & $0.17 \sim 0.73$ \\
\hline & & Some ameliorated & 0.53 & 0.058 & $0.28 \sim 1.02$ \\
\hline & & Greatly ameliorated (reference) & 1.00 & & \\
\hline \multirow{4}{*}{$\begin{array}{c}\text { Social } \\
\text { circumstances }\end{array}$} & \multirow{2}{*}{ INTNET } & Yes & 0.33 & 0.065 & $0.10 \sim 1.07$ \\
\hline & & No (reference) & 1.00 & & \\
\hline & \multirow{2}{*}{ PROPA* } & Yes & 1.38 & 0.047 & $1.00^{\sim} 1.89$ \\
\hline & & No (reference) & 1.00 & & \\
\hline
\end{tabular}

Abbreviation: $\mathrm{Cl}=$ confidence interval. ${ }^{*} \mathrm{p}<0.05,{ }^{* *} \mathrm{p}<0.01,{ }^{* * *} \mathrm{p}<0.001$

Second, as noted by Zhu and Li (2014), in order to maintain or even increase the household income after the implementation of the KGPSRB, the government provided subsidies to farmers for building greenhouses to grow vegetables. However, although over $80 \%$ of the respondents stated that developing greenhouse agriculture could improve household income (mentioned earlier in this study), the result from the logistic regression model indicated that farmers who built and used greenhouses indicated a lower satisfaction of the policy effects. One of the major reasons for this is that modern agriculture requires a higher education level for farmers to master these technologies. However, the school education level of most farmers who put these technologies into practice in person have less than nine years compulsory education, which is a barrier for them to completely master these key skills. On the other hand, owing to the asymmetric market information for the supply and demand of agricultural products and the dearth of diversified marketing channels for agricultural products, all these factors mentioned above together resulted in low profits from greenhouses, or at least the expected results were not achieved. A potential consequence of this result as noted by Cao et al. (2009) that if the policy cannot improve the livelihood of local residents, it will be unable to restore degraded environments.

In addition, farmers' predictions of environmental change in the future are based on their awareness of currently environmental state after the policy intervention. Thus, if farmers foresee that the local ecosystem will change for the worse, the effect of the policy is negative, and they tend to be dissatisfied with the policy effectiveness. Just as 
Kleftoyann et al. (2011) pointed that farmers scored lower in their environmental perceptivity, nevertheless, they were highly aware that some of their practices have negative impacts on the environment.

Finally, concerning the factors of social circumstance, the study findings indicate that only existed two sources for policy information significantly influenced the farmers' satisfaction level of the policy effectiveness. First, the direction of the influence was surprisingly negative for households with access to policy information derived from the internet. This may be attributed to the internet as a new channel of information dissemination, of which the contents are diverse; the internet not only includes positive information reports but also contains various negative comments or even rumors related to policy implementation, and the latter is a more likely cause for concern. For this reason, farmers often have a low evaluation of policy effectiveness. However, our finding showed that only a few farmers had access to policy information by using the internet. Moreover, as discussed by Tucker and Napier (2002), while online methods are rapidly gaining more information, traditional and face-toface channels are still important for reaching many farmers. In remote rural areas of China, especially, the village administrators' announcement has always been an important traditional channel for disseminating policy information. This is similar to the findings of Ajayi and Kwesiga (2003) who reported that the most important source of the bylaws was the village headsmen in eastern Zambia, and this was a significant factor that influenced the level of farmers' awareness of the effectiveness of the bylaws. This type of association shown in the current study is also consistent with Yiridoe et al. (2010) who pointed out that the traditional channels (such as interpersonal sources and government agencies, etc.) were used more commonly compared with mass media such as electronic and computer channels.

\section{Conclusions}

As a case study, this paper investigates the effects of the policy impacts from farmers' perception. The results show that farmers' perception of policy effectiveness appeared consistent with the evidences of the policy implementation outcomes reported in previous studies and official statistics. However, farmers had a low level of satisfaction with respect to two main policy measures, i.e., the ecological migration, and the closing motor-wells and reducing the irrigated farming acreage. The results of the ordinal logistic regression model showed that $62 \%$ of the variance in the probability of the farmers' satisfaction level of policy implementation could be explained by predictor variables at higher levels. We conclude that farmers' perception of policy effectiveness is an outcome of the overall influence of individual characteristics, social, economic, and cognitive factors that act at different levels.

\section{Acknowledgements}

This research was supported by the National Social Science Foundation of China (No. 11BSH059) and the International Innovation Team Project of Chinese Academy of Sciences entitled "The process of climate-hydrology-ecology and the sustainable utilization of water resources in pan-Hexi region" (No. Y42AC71001). The authors especially thank the anonymous referees for commenting on the earlier version of the article.

\section{References}

Ajayi O.C. and Kwesiga F. (2003), Implications of local policies and institutions on the adoption of improved fallows in eastern Zambia, Agroforest Systems, 59, 327-336.

Ananth V.C. and Kleinbaum G.D. (1997), Regression models for original responses: A review of methods and applications, International Journal of Epidemiology, 26, 1323-1333.

Anderson J.A. and Philips P.R. (1981), Regression, discrimination and measurement models for ordered categorical variables, Journal of Royal Statistical Society, Series C (Applied Statistics), 30, 22-31.

Cao S., Zhong B., Yue H., Zeng H. and Zeng J. (2009), Development and testing of a sustainable environmental restoration policy on eradicating the poverty trap in China's Changting County, Proceeding of the National Academy of Sciences, 106, 1071210716.

Chambers R. and Conway G. (1992), Sustainable rural livelihoods: practical concepts for the 21st century, Institute for Development Studies, Brighton.

Danfeng S., Hong L. and Baoguo L. (2008), Landscape connectivity changes analysis for monitoring desertification of Minqin county, China, Environmental Monitoring and Assessment, 140, 303-312.

De Stefano L., Gilsanz Jde P. and Gil F.V. (2010), A methodology for the evaluation of water policies in European countries, Environmental Management, 45, 1363-1377.

Dong Z., Man D., Luo W., Qian G., Wang J., Zhao, M., Liu S., Zhu G. and Zhu S. (2010), Horizontal aeolian sediment flux in the Minqin area, a major source of Chinese dust storms, Geomorphology, 116, 58-66. 
Feng Q., Miao Z., Li Z., Li J., Si J., S Y. and Chang Z. (2015), Public perception of an ecological rehabilitation project in inland river basins in northern China: Success or failure, Environmental Research, 139, 20-30.

Feng S., Huo Z., Kang S., Tang Z. and Wang F. (2010), Groundwater simulation using a numerical model under different water resources management scenarios in an arid region of China, Environmental Earth Sciences, 62, 961-971.

Fuks M. and Salazar E. (2008), Applying models for ordinal logistic regression to the analysis of household electricity consumption classes in Rio de Janeiro, Brazil, Energy Economics, 30, 1672-1692.

Huang S., Zhou L., Chen Y. and Lu H. (2014), Impacts of policies on eco-environment of Minqin county during the past 60 years, Journal of Arid Land Resources and Environment, 28, 73-78 (in chinese).

Karali E., Brunner B., Doherty R., Hersperger A. and Rounsevell M. (2014), Identifying the factors that influence farmer participation in environmental management practices in Switzerland, Human Ecology, 42, 951-963.

Kerselaers E., Rogge E., Vanempten E., Lauwers L. and Van Huylenbroeck G. (2013), Changing land use in the countryside: Stakeholders' perception of the ongoing rural planning processes in Flanders, Land Use Policy, 32, 197-206.

Khanmtr and Omprakash M.D. (2016), Adaptation through watershed management in the changing climate, Global NEST Journal, 18, 11-24.

Kleftoyann V., Abakoumkin G. and Vokou D. (2011), Environmental perceptions of students, farmers, and other economically active members of the local population near the protected area of Axios, Loudias and Aliakmonas estuaries, in Greece, Global NEST Journal, 13, 288-299.

Li Y., López-Carr D. and Chen W. (2014), Factors affecting migration intentions in ecological restoration areas and their implications for the sustainability of ecological migration policy in arid northwest China, Sustainability, 6, 8639-8660.

Liu X. and Cai Y. (2014), Analysis of farmers' satisfaction on the implementation of cultivated land protection fund and influencing factors: A case study of Yongan Town, Jinqiao Town and Jiangyuan Town in Chengdu City, Journal of China Agricultural University, 19, 216-223 (in Chinese).

Luo W. (2011), Analysis on the effect of policies implemented in rural China and its determinants: Based on the perspective of village administrator, Chinese Rural Economy, 1, 15-26 (in Chinese) .
Maas R., Kruitwagen S. and van Gerwen O.-J. (2012), Environmental policy evaluation: Experiences in the Netherlands, Environmental Development, 1, 67-78.

Manoliadis O.G. and Vatalis K.I. (2003), An environmental impact assessment decision analysis system for irrigation systems, Global NEST Journal, 5, 65-70.

Maraqa M.A. and Ghoudi K. (2015), Survey of public attitudes towards bottled and tap water quality in the use, Global NEST Journal, 17, 607-671.

Mouratidis I., Dimopoulos G., Astaras T. and Savvidis S. (2010), Sustainable water resources management through the use of GIS technologies, Global NEST Journal, 12, 140-151.

Ranatunga T., Tong S.T.Y., Sun Y. and Yang Y.J. (2014), A total water management analysis of the Las Vegas Wash watershed, Nevada, Physical Geography, 35, 220-244.

Ren X., Yang X., Wang Z., Zhu B., Zhang D. and Rioual P. (2014), Geochemical evidence of the sources of aeolian sands and their transport pathways in the Minqin Oasis, northwestern China, Quaternary International, 334-335, 165-178.

Shui W., Bai J., Zhang S. and Chen Y. (2014), Analysis of the influencing factors on resettled farmer's satisfaction under the policy of the balance between urban construction land increasing and rural construction land decreasing: A case study of China's Xinjin County in Chengdu City, Sustainability, 6, 8522-8535.

Tucker M. and Napier T.L. (2002), Preferred sources and channels of soil and water conservation information among farmers in three midwestern US watersheds, Agriculture Ecosystems and Environment, 92, 297-313.

Wouterse F. (2010), Migration and technical efficiency in cereal production: evidence from Burkina Faso, Agricultural. Economics, 41, 385-395.

Xue X., Liao J., Hsing Y., Huang C. and Liu F. (2015), Policies, land use, and water resource management in an arid oasis ecosystem, Environmental. Management, 55, 1036-1051.

Yiridoe E.K., Atari D.O.A., Gordon R. and Smale S. (2010), Factors influencing participation in the Nova Scotia Environmental Farm Plan Program, Land Use Policy, 27, 1097-1106.

Zhu Q. and Li Y. (2014), Environmental restoration in the Shiyang River Basin, China: Conservation, reallocation and more efficient use of water, Aquatic Procedia, 2, 24-34. 